\title{
Las minas marinas del Golfo de California: del extractivismo a la sustentabilidad
}

Marine Mines of the Gulf of California: from Extraction to Sustainability

\section{Micheline Cariño}

UNIVERSIDAD AUTÓNOMA DE BAJA CALIFORNIA SUR (UABCS),

marthamichelinecarino@gmail.com

\section{Mario Monteforte}

CENTRO DE INVESTIGACIONES BIOLÓGICAS DEL NOROESTE (CIBNOR), montefor04@cibnor.mx

Las ostras perleras son moluscos bivalvos marinos productores de nácar y perlas. Los pueblos originarios del Golfo de California las consumían como alimento, luego, entre 1533 y 1939, las conchas y las perlas naturales fueron el principal producto comercial marino. Tuvieron una explotación comparable a las minas de metales por las formas de apropiación asimétrica del espacio y la explotación del trabajo. En los puertos regionales, el trasiego de las armadas perleras detonó la navegación y el comercio. En 1940 el recurso se agotó debido al impacto del buceo mecanizado (desde 1874), a la destrucción de la Compañía Criadora de Concha y Perla (1914) y a cambios ambientales. Actualmente, el cultivo extensivo de ostras perleras, combinado con el de especies comestibles, puede contribuir a la sustentabilidad regional. Empleamos la larga duración para dar un recuento de la historia ambiental de uno de los principales recursos pesqueros del Golfo de California.

PALABRAS CLAVE: historia ambiental; perlas y nácar; Golfo de California; sustentabilidad.

Pearl oysters are marine bivalve mollusks that produce nacre and pearls. They long formed part of the diet of native peoples around the Gulf of California, but from 1533 to 1939 shells and natural pearls were the most important commercial marine products. Indeed, their production can be compared to that of metal mining, because of the asymmetric nature of the means of appropriating space and the exploitation of labor. In regional ports, the constant traffic of pearl fleets propelled navigation and international trade. In 1940, however, this natural resource was exhausted by the introduction of mechanized diving (since 1874), the collapse of the Compañia Criadora de Concha y Perla (1903-1914), and environmental change. Today, the extensive farming of pearl oysters, combined with edible mollusks, may signal a path towards regional sustainability. We adopt a long-term approach to analyze the environmental history of one of the most important fishery resources in the Gulf of California.

KEYWORDs: environmental history; pearls and nacre; Gulf of California; sustainability.

Fecha de recepción: 28 de noviembre de 2016 / Fecha de aprobación: 14 de junio de 2017 / Fecha de recepción de la versión final: 25 de junio de 2017 


\section{INTRODUCCIÓN}

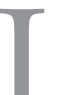

as ostras perleras se encuentran prácticamente en toda la zona costera tropical-templada del Planeta pero sólo ciertas especies han sido apreciadas comercialmente (pesca y cultivo) por el tamańo de la concha y calidad de nácar, y la eventual incidencia de bellas perlas naturales. Básicamente se trata de 8 especies distribuidas en dos géneros de la familia Pteriidae, 6 en el género Pincta$d a$, conocidas como madreperlas, y 2 en el género Pteria o concha nácar. Por la historia de su explotación pesquera intensiva identificamos once regiones biogeográficas y, evidentemente, culturales (Carińo y Monteforte 2006). En los litorales que fueron habitados por grupos de cazadores recolectores, el principal uso fue alimenticio. No obstante, todas las sociedades humanas han apreciado la belleza del nácar y las perlas, y los han portado como ornamentos.

Uno de los principales motivos para colonizar América fue la riqueza perlera que los primeros exploradores españoles encontraron en la región Caribe-Antillas (P. imbricata y Pt. colymbus, especies de talla pequeña como la madreperla japonesa). Asimismo, la primera razón para expandir el virreinato de la Nueva Espańa hacia el noroeste fue la riqueza de los placeres perleros que luego hallaron en el Golfo de California (P. mazatlanica y Pt. sterna, de talla parecida a la madreperla negra de Polinesia Francesa). Desde 1533 hasta 1939, estos placeres o yacimientos tuvieron una explotación comparable a la de las minas de metales preciosos en cuanto a las formas de apropiación asimétrica del espacio marino y la explotación del trabajo de los buzos, tanto indígenas como mestizos. Para los puertos del Golfo, el trasiego de las armadas perleras significó un detonante para la navegación de cabotaje y el comercio internacional que alimentó la ávida demanda de los mercados suntuarios del mundo y la enorme industria europea de la botonería y las manufacturas con nácar (Monteforte y Cariño 2012).

En la historia de las ostras perleras del Golfo de California es posible identificar ciclos de abundancia y escasez mientras la explotación estuvo llevándose a cabo con base en el buceo tradicional. A partir de la introducción de la escafandra en la región (1874), la extracción mecanizada amplió los límites humanos de profundidad y pudo rea- 
lizarse en todas las temporadas del ańo. En 1939, el alto impacto pesquero llevó las dos especies al agotamiento. Sin embargo, este fenómeno pudo haber sucedido antes si no hubiera existido el efecto reproductor que tuvo la Compañía Criadora de Concha y Perla de la Baja California S.A. (a partir de ahora abreviada CCCP), dirigida por el empresario y científico sudcaliforniano Gastón J. Vives. Esta pujante empresa fue destruida durante los eventos de la Revolución en 1914, segando un extraordinario potencial productivo para la región.

Desde entonces y hasta 1980, los intentos por recuperar el cultivo de las ostras perleras fueron infructuosos, si bien en la última década del siglo xx la innovación científica local, basada en la experiencia de Vives, permitió el desarrollo de dos granjas perleras privadas. Antes de la entrada de los chinos al mercado mundial de perlas marinas (hacia 2005), esta actividad económica podía alcanzar rendimientos extraordinarios; lo que avivó la codicia científico/empresarial y, por complejas circunstancias, impidió trasferir la tecnología al sector social regional, dando al traste con la posibilidad de convertir la perlicultura en una estrategia de desarrollo comunitario (Monteforte y Cariño 2012). Ahora, combinar el cultivo extensivo de ostras perleras con el de otras especies comerciales, puede aun ser una alternativa económica viable para las comunidades de pescadores artesanales, además de ser una actividad productiva ambientalmente beneficiosa, por lo que contribuye a la sustentabilidad regional. Comentario al margen, esta modalidad técnica-policultivo extensivo y semiextensivo en condiciones de campo- es materia de desarrollo piloto en el CIBNOR y otros casos a nivel nacional e internacional.

En este trabajo transitamos por un tiempo de larga duración y empleamos la historia ambiental marina para hacer un recuento crítico y sintético de uno de los principales recursos pesqueros que en el pasado, presente y futuro, ha tenido, tiene y tendrá el Golfo de California.

\section{Ostras PERleras, AMBiEnTE Y SOCIEDADES}

La historia ambiental y etnobiología en torno a un recurso pesquero clave no pueden entenderse sin estudiar el análisis de perfil de dicho recurso (e.g. Cariño 1996; Narchi et al., 2014; Saslis-Lagoudakis y 
Clarke 2013). Es crucial empezar por conocer su modo de vida con el mayor detalle posible y enseguida examinar los aspectos multifactoriales mediante los cuales se expresan las relaciones del recurso con las sociedades costeras y viceversa. Debido a restricciones de espacio, será necesario realizar un apretado resumen temático con el principal propósito de proveer información dirigida a lectores no especialistas, la cual es fundamental para comprender por qué y cómo la pesca irracional fue la principal causa que llevó a los otrora ricos placeres perleros a estado casi de extinción en todo el mundo y, al mismo tiempo, fue el motor de investigación científica que derivaría, a partir de los cincuenta del siglo pasado, hacia el multimillonario negocio de las granjas perleras modernas.

Empecemos, pues, con recordar que desde la etapa juvenil y por el resto de su vida, las ostras perleras se encuentran permanentemente adheridas a fondos duros (i.e. especies sésiles) mediante un órgano fibroso llamado byso, parecido a la raíz de un árbol. Viven entre 1 y 35 metros de profundidad, o más hondo, en aguas claras y cálidas. Las poblaciones se desarrollan mejor en sitios protegidos de fuertes corrientes y oleaje.

$\mathrm{Al}$ madurar sexualmente, machos y hembras lanzan al agua millones de gametos que en gran mayoría se pierden sin ser fecundados, apenas un porcentaje mínimo logran formar larvas. Estos diminutos seres se dispersan a la deriva 30-40 días en busca de sustrato apropiado para fijación. Mientras tanto, y aún después a lo largo de su vida, enfrentan a diversos predadores y siempre son afectados por cambios bruscos de temperatura, salinidad, composición del agua, corrientes y otros factores oceanográficos. En otras palabras, la abundancia y densidad de adultos reproductores en sitios estratégicos (incluyendo granjas perleras entre dichos sitios) son factores indispensables para asegurar la productividad de la población.

Huelga reiterar que la más destacada característica que los humanos han apreciado en estos moluscos es la producción de concha nacarada. El nácar, un compuesto biomineral formado por una matriz proteica de conchyolina sostenida por un entramado de cristales de carbonato de calcio y otros minerales cuya estructura se denomina aragonita en el ámbito de la Geología y Mineralogía, como refe- 
rencia a las minas de Aragón, España, de donde se extrae este material principalmente para uso decorativo y productos diversos en torno al polvo de carbonato de calcio (por ejemplo, fabricación de suplementos alimenticios y para pulido de cristal óptico, piedras preciosas y metal fino). La parte interna de las valvas de ostras perleras está recubierta por nácar liso que despliega gran variedad de colores y reflejos tornasol al difractar la luz. En términos de perlería, esta propiedad se le conoce como "oriente".

La formación de perlas naturales obedece a una respuesta normal que exhiben los moluscos conquíferos, como las ostras perleras, ante circunstancias al azar; es decir, puede suceder que sean presa de depredadores o huéspedes de diversos organismos epibiontes que perforan la concha para alimentarse del cuerpo blando o practican excavaciones y ranuras que debilitan así su consistencia. Con suerte la víctima es capaz de regenerar concha externa mediante anillos de crecimiento o formando una especie de tapón o ampolla dura desde el interior. En las ostras perleras de este proceso algunas veces resultan bellas medias-perlas y formaciones asombrosas recubiertas de nácar. Además, los bivalvos son filtradores suspensívoros, es decir, que toman oxígeno y nutrientes sólidos y disueltos mediante recambio de agua gracias a pulsaciones de varios órganos (músculos, manto, aparato digestivo, branquias, etcétera). Accidentalmente, un objeto puede alojarse en partes blandas que provocan irritación que el animal contrarresta recubriéndola con capas concéntricas de nácar hasta formar un grano liso que eventualmente puede expulsar. Es extremadamente raro que estos granos lleguen a alcanzar la perfección que les confiere ser considerados perlas, incluso en clásicos moluscos comestibles como ostión, escalopa, almejas y algunos caracoles. Tanto la belleza de estas joyas como su rareza son factores que han convertido el sufrimiento de estos animales. Principalmente, las ostras perleras han producido las más antiguas gemas valoradas y codiciadas por la humanidad. Los criterios de calidad han variado a través de tiempos y culturas, pero generalmente se consideran tamańo, textura, color y oriente (Joyce y Addison 1992) cuya gradación depende de parámetros oceanográficos (circulación, nutrientes, temperatura, salinidad y concentración de carbonato de 
calcio y de silicio) (Wada 1961), así como del manejo de los animales en condiciones de cultivo y del dominio de las técnicas de perlicultura.

La restringida distribución geográfica de las ostras perleras retardó, hasta principios del siglo xx, el conocimiento científico sobre la formación de las perlas y el cultivo de los animales que las crean. Si bien, los chinos desde el siglo $v$ entendieron el origen de las perlas (de agua dulce) y lograron producirlas a escala de souvenir para peregrinos (perlas de Buda), los europeos en el siglo XviII seguían creyendo en diversos mitos, la mayoría de ellos provenientes de India y Persia donde abundaron estas gemas cuya supuesta utilidad medicinal -hasta con influencias de magia- es tan antigua como común en Oriente.

Clasificamos en tres grupos las once regiones perleras del mundo con base en su incorporación al comercio mundial, ya que esto implicó una transformación del valor de uso que asignaron los pueblos originarios a las ostras perleras, al valor de cambio que tuvieron las minas marinas para las empresas que se dedicaron a su explotación (Cariño y Monteforte 2006). Su intensidad fue proporcional a los medios humanos, económicos y técnicos que lo permitieron. El Golfo Pérsico, el de Manar y el Mar Rojo, forman el primer grupo y estas regiones fueron explotadas desde la Antigüedad. La colonización de América, en el siglo Xvi, incorporó al mercado europeo las perlas del Caribe y del Golfo de Panamá y del de California. Por último, en el siglo xIx, la expansión colonial en África, Asia y Oceanía, forma el tercer grupo que incluye los ricos placeres perleros del Pacífico Sur y de la costa sudoriental de África.

Por su forma y dimensiones, el Golfo de California puede ser considerado mar interior, y además es el único mar propiedad de una sola nación. Mide más de 1,300 km de largo, tiene 3,000km de litoral y posee más de 17,000 islas e incidentes insulares. Su larga orientación norte-sur lo distingue de otros mares interiores del mundo y le confiere la particularidad de incluir dos regiones zoogeográficas generales, una tropical y una templada. Las dimensiones y características de esta cuenca determinan un dinámico y complejo sistema de corrientes, surgencias, y movimiento de grandes cuerpos 
de agua. Brusca y Wallernstein (1979) introdujeron el término subtropical para definir la biogeografía de su medio marino. Aquí suceden grandes fluctuaciones latitudinales de temperatura y salinidad a causa de la dinámica de masas de agua, elevada insolación y escaso aporte de agua dulce (por falta de lluvias y ríos). Esta última situación se agravó desde los cuarenta en adelante con la construcción de las presas Hoover y Glen en los EE.UU., lo que contribuyó al empobrecimiento de los placeres perleros que afectaron también a muchas otras especies sensibles a estos cambios ambientales. En promedio la temperatura invernal varía entre $10^{\circ} \mathrm{C}$ y $12^{\circ} \mathrm{C}$, y la estival entre $30^{\circ} \mathrm{C}$ y $32^{\circ} \mathrm{C}$, con picos que pueden llegar hasta $38^{\circ} \mathrm{C}$ en el norte. Las profundidades son muy variables. En su primer tercio, al norte de las islas Tiburón y Ángel de la Guarda, cerca de $50 \%$ de los fondos se encuentran por arriba de los $200 \mathrm{~m}$. En los dos tercios restantes son comunes profundidades que superan los $3,500 \mathrm{~m}$. Los fenómenos de surgencia que generan estas profundidades, aunados a los numerosos esteros y lagunas costeras, explican su elevada productividad biológica, y la consecuente biodiversidad marina. Sin embargo, cualquier leve cambio en la composición del agua y en el equilibrio de este excepcional ecosistema puede tener efectos catastróficos en el ciclo de vida de las comunidades naturales.

La madreperla P. mazatlanica y la concha nácar Pt. sterna se distribuyen ampliamente desde el paralelo $30^{\circ} \mathrm{Ny}$ Golfo de California hasta el archipiélago de Galápagos y Perú, aunque sólo el Golfo de California y el de Panamá son regiones reconocidas por la abundancia de estas especies y la elevada incidencia de perlas naturales en ellas. Por la calidad del nácar, el tamaño de las conchas y los tonos claros de sus perlas, $P$. mazatlanica fue siempre más apreciada. La concha nácar Pt. sterna ocupó un papel comercial secundario aunque la pesca fue igualmente intensiva. Por ser filtradoras, estas especies desempeñan funciones tanto fundamentales como complementarias en la red trófica del Golfo de California. La madreperla es más selectiva en cuanto a las características de su hábitat, mientras la concha nácar ocupa biotopos con características menos favorables para la primera con respecto a corrientes, claridad del agua, tipos de substrato y profundidad. Sus épocas reproductivas 
ocurren en temporadas diferentes. Estas características fueron de suma importancia en la explotación pesquera y en las experiencias históricas y contemporáneas de cultivo.

Ambas especies han sido un importante recurso en la cultura y desarrollo de las sociedades regionales desde la época prehispánica hasta la actualidad. Sin embargo, el impacto de la pesca, cultivo y comercio ha variado en tiempo y espacio, tanto por el perfil propio de cada especie, como por la carencia de otros recursos disponibles. La distribución de las poblaciones en el Golfo es heterogénea; los placeres se concentran en las costas occidentales, en especial, en las bahías de Los Frailes, La Paz, Loreto y Los Ángeles, así como en las principales islas (Tiburón, San José, Espíritu Santo y Cerralvo). Comparativamente, en la costa oriental y alto Golfo la existencia de placeres perleros fue escasa, pero otro tipo de recursos, en especial tierra fértil y agua dulce, fueron mucho más abundantes que en la península. Por estas circunstancias, la historia perlera del Golfo de California se vincula más con el devenir de la península que con el de la contracosta.

\section{BUCEO TRADICIONAL: INDÍGENAS Y EXPLOTACIÓN COLONIAL (SIGLOS XV-XIX)}

En la historia, la pesca de ostras perleras se ha llevado a cabo en dos modalidades de buceo: el tradicional (o de chapuz, como se le conocía antes en la región) y el mecanizado con escafandra, dragas, aparatos de arrastre o buceo autónomo). En este apartado analizaremos la primera modalidad, la cual en nuestra región de estudio, al igual que en otras regiones perleras del mundo, se empleó desde los primeros años de la ocupación humana hasta la introducción y posterior industrialización de medios mecánicos.

Los pueblos originarios que aprovecharon y poblaron las costas americanas donde había ostras perleras las extrajeron con la finalidad de alimentarse, aunque no fueron indiferentes a la belleza de las perlas y a la utilidad de las conchas, empleadas respectivamente como adornos y herramientas. Desde los primeros contactos que los exploradores españoles tuvieron con los habitantes de las islas del 
Caribe notaron adornos de pulseras y collares de perlas, lo que les alertó de su existencia. Cabe señalar que las perlas fueron la primera y la principal motivación para la expansión española en América (Galstoff 1950), la búsqueda de metales preciosos vendría después; esto se debe a que fue más difícil saber de su existencia y realizar extracciones. Al Caribe le siguieron las costas del Pacífico, primero el Golfo de Panamá y el Archipiélago de las Perlas y, posteriormente, el Golfo de California e islas. En todos los casos, el buceo indígena fue la única manera de obtener las preciadas gemas.

El aislamiento de la península y su compleja orografía y aridez obligaron a los primeros habitantes a desarrollar rigurosas y eficientes estrategias adaptativas. Éstas tuvieron como base una organización socioespacial donde los territorios de colecta, caza y pesca estaban estrictamente delimitados y la ocupación era itinerante acorde con las estaciones. A lo largo del año, bandas o tribus transitaban de la montańa a la playa y viceversa, deteniéndose temporalmente en parajes dotados de fuentes de agua permanente. El uso de la costa y recursos varios se realizaba en la época de bonanza, por lo general, en correspondencia con las lluvias de verano. La abundancia de recursos permitía entonces un relajamiento de trabajo y la distensión de conflictos internos y entre bandas; era el momento de intercambiar mujeres; efectuar los ritos de iniciación de adolescentes; y realizar festines, para esto recolectaban pitahayas, ciruelas, moluscos y tortugas marinas, que eran los principales elementos del menú. Algunos miembros del grupo Pericú que habitó la porción sur de la península ocuparon de manera casi permanente la zona costera y las islas aledańas a la Bahía de La Paz. Fueron ellos quienes más aprovecharon los recursos marinos y los únicos que dominaron la navegación (Reygadas y Velázquez 1983). No es de extrañar que hayan sido también los mejores buzos y principales colectores de nácar y perlas, consecuentemente fueron los primeros en ser contactados por exploradores y conquistadores en busca de riqueza.

En 1533, los europeos al fin se toparon con California, tierra de amazonas y perlas según las novelas de caballería. Entonces Fortún Ximenez (piloto amotinado de una de las expediciones enviadas por Hernán Cortés al Pacífico) y su tripulación tuvieron el primer con- 
tacto con sus habitantes (Del Río 1985). De inmediato, el destello de las perlas y ornamentos de nácar que los nativos portaban como adorno personal, llamó la atención de los españoles; al pretender arrebatarles sus pertenencias, fueron agredidos al parecer letalmente. Los sobrevivientes llevaron la noticia a Cortés quien encabezó la siguiente expedición con la intención de fundar una colonia. Llegó a lo que hoy es Bahía de La Paz el 3 de mayo de 1535, por lo que en honor de la fecha llamó Puerto y Bahía de La Santa Cruz al lugar donde celebró el Primer Auto de Posesión en nombre del rey (Coronado 1982). Dos años después, a pesar de grandes esfuerzos y sumas de dinero invertidas, Cortés tuvo que abandonar la incipiente colonia. Tras este primer intento siguieron diecisiete décadas de expediciones, todas ellas teniendo como principal objetivo la pesca de nácar y perlas antes de que los jesuitas en 1697, con un propósito completamente distinto, lograran por fin concretar la colonización de la península.

La Corona, sabedora de la codicia que despertaban esas gemas en marinos y exploradores, desde 1586 decretó propiedad sobre los placeres perleros. Para tener acceso era indispensable contar con licencia y pagar el quinto de perlas (regulación idéntica a la de las minas de metales preciosos). Esta medida capitalizaba al real erario por partida doble, pues, no sólo recibía la quinta parte de la riqueza perlera extraída, sino además se ahorraba fuertes inversiones necesarias para realizar la exploración de tan alejadas tierras y mares. Así, a las empresas que solicitaban licencia perlera para el Golfo de California se les requería también que buscaran un lugar apropiado para fundar una colonia (de vital importancia en el torna viaje de la Nao de China) y que demarcaran las costas. Todos los esfuerzos colonizadores entre 1580 y 1683 fueron encomendados a las expediciones perleras, de ahí que el siglo XVII sea conocido en la historiografía regional como la época de los buscadores de perlas (Mathes 1973). Los resultados de esta política fueron frustrantes. Todas las expediciones fracasaron en el propósito de asentar un real y el saldo de la pesca fue inconstante, algunas veces los reportes, cuando eventualmente se hacían, daban cuenta de la riqueza de los placeres y otras de su agotamiento. La alternancia de estos ciclos es la consecuencia 
de una intensiva explotación, seguida de un tiempo de reposo inducido por los bajos rendimientos (Cariño 1998).

En un principio, los empresarios empleaban buzos pericues y años más tarde (a fines del siglo XVIII) empezaron a traer yaquis reclutados en los pueblos costeros de Sonora. En todo caso, la destreza que los indígenas desplegaban para el buceo obligó a los empresarios perleros a depender de su trabajo y, consecuentemente, ceder acuerdos laborales. La temporada de buceo se desarrollaba entre mayo y octubre cuando el sol ilumina mejor los fondos y el agua es templa$\mathrm{da}$, pero sobre todo cuando era posible encontrar a los indígenas en la costa. Las flotas de pesca, también conocidas como "armadas perleras", consistían en un conjunto de embarcaciones, una principal y varias pequeñas (Esteva 1857). En los primeros meses del año, las armadas perleras se constituían en las costas continentales donde se aprovisionaban de alimentos y marineros. Los armadores (capitanes de las armadas) establecieron ingeniosos medios de comunicación no verbal con los indígenas a quienes retribuían por el buceo con artefactos diversos y alimentos. Cuando no se concretaba el acuerdo, los indígenas rechazaban trabajar y simplemente se iban. Esta situación perjudicaba sobremanera la empresa, por lo que los malos tratos y el trabajo forzado fueron comunes a pesar de ser prohibidos por la Corona desde 1586. Por esta razón, durante el periodo de ocupación jesuita (1697-1768), la pesca de perlas fue estrictamente prohibida (Cariño 1998).

El método del buceo de chapuz era muy sencillo. A bordo de las pequeñas embarcaciones los buzos se tiraban al agua sobre un placer previamente identificado. Llevaban consigo un cuchillo para desprender las ostras del fondo y un saco de red para colectarlas. Eventualmente, el cuchillo les serviría también para defenderse de cualquier animal que les agrediera. A lo largo de la mańana llenaban el saco de ostras, permaneciendo largo rato en el fondo, sumergiéndose en múltiples ocasiones y hasta una profundidad de 20 metros (Cariño 1998). Hacia el final de la época colonial, cuando los pericues se habían extinto, y hasta la introducción de la escafandra (en 1874), las armadas emplearon buzos yaquis y también mestizos sudcalifornianos, con quienes ya se comunicaban en español. Entonces la 
retribución se llevaba a cabo en especie: de cada cinco ostras, una era para pagar el impuesto, dos para el armador y dos para el buzo. Las ostras se mantenían cerradas hasta que eran separadas en la embarcación mayor frente al armador, con la finalidad de obligar a los buzos a vender a éste las perlas que hubieran contenido las ostras que les correspondían. De esta manera, los buzos pagaban el dinero, que les habían entregado como anticipo, y la alimentación que recibían durante la temporada. Debido al bajo precio en el que se veían obligados a vender sus perlas y al elevado costo de los avíos, al final de la temporada generalmente no lograban saldar sus deudas, y quedaban enganchados para la próxima temporada. El trabajo forzado, las pésimas condiciones para desempeńarlo y el endeudamiento permanente de los trabajadores, frente a los elevados niveles de acumulación de riqueza por parte de los propietarios de las armadas, permiten comparar el buceo de perlas, en minas marinas, con la extracción de metales preciosos en minas terrestres (Cariño 1998).

En 1830 hubo un cambio importante en la extracción de los placeres perleros del Golfo de California. Cipryen Combier, un comerciante francés que visitó entonces La Paz, observó en la playa cerros formados por las conchas de madreperla y concha nácar que se encontraban abandonados en la playa. Hasta entonces las conchas eran desechadas y sólo se comerciaba con las perlas. Combier decidió lastar su barco acumulando toneladas de conchas (Diguet 1895). A partir de entonces, los empresarios perleros empezaron a valorar este nuevo recurso y la exportación de concha creció constantemente, lo que tuvo un impacto multiplicador en los puertos de altura del golfo. El tamaño y la cantidad de las armadas perleras también aumentaron. Sin embargo, el incremento del esfuerzo pesquero no tuvo consecuencias devastadoras en los placeres debido a que la rentabilidad de las actividades de las armadas dejó de depender del azaroso hallazgo de perlas naturales con valor comercial, que requería el sacrificio de miles de ostras. El nuevo interés por las conchas en términos de su cantidad de nácar poco a poco fue sustituyendo a las perlas. Así, el buceo se intensificó convirtiéndose en la principal actividad económica del puerto de La Paz y en una actividad sobresaliente en otros puertos del golfo (Monteforte y Carińo 2012). 
BUCEO MECANIZADO: EXTRACCIÓN MODERNA DE NÁCAR Y PERLAS (I874-I939)

Hacia 1870, la sobreexplotación de los placeres perleros de todas las regiones del mundo amenazaba la continuidad de lo que había sido un jugoso negocio, por lo que la solución tecnológica mediante la introducción de la escafandra fue gran alivio para las actividades extractivistas de nácar y perlas. Ese año se inició el buceo con escafandra en los placeres australianos y cuatro años después el invento llegó al Golfo de California proveniente de Panamá donde había enriquecido a los empresarios Bosi y Clarte, quienes lo introdujeron a la región (Cariño 1998).

La innovación modificó radicalmente el trabajo de las armadas y la gestión pesquera de los placeres. El buceo mecanizado permitió extraer animales que se encontraban a profundidad no alcanzable por los buzos de chapuz, y esto durante todos los meses del ańo. Las ganancias de las primeras temporadas fueron inmensas de manera que los empresarios perleros apostaron a la cuantiosa inversión que implicaba comprar aparatos e infraestructura y contratar buzos especializados. Por ello, los fuertes desembolsos debían tener sólido respaldo institucional que les garantizara acceso a las minas marinas del Golfo de California. El gobierno porfirista, ávido de inversión productiva extendió el mecanismo de las concesiones territoriales, hasta entonces reservado a las políticas de colonización, a la explotación de los recursos perleros. Esto suscitó la formalización de compañías perleras -con capital nacional y extranjero- que solicitaban en concesión exclusiva determinadas zonas de placeres (Carińo 1996a).

La concesión territorial para la pesca de nácar y perlas se realizaba mediante firma de convenio entre los socios o apoderados de la compañía y el gobierno federal, representado por la Secretaría de Fomento. En 1884 se otorgaron concesiones de este tipo a seis compañías formadas por empresarios locales. Después, los territorios concesionados tendieron a expandirse mientras que el número de compañías se redujo, se generó así un fenómeno de concentración tanto de concesiones como de capitales. A finales del siglo xIX, mediante fusión empresarial y cesión o venta de derechos, la extracción 
de los placeres perleros de México se convirtió prácticamente en un monopolio en manos de la Mangara Exploration Company Ltd. de capital británico, conocida localmente como La Mangara. Esta compañía se fundó en 1899 a partir de la cesión de derechos concesionados a la Compañía Perlífera de Baja California en 1894. El primer contrato de concesión de La Mangara tenía vigencia por siete años, pero en 1904 ese plazo fue ampliado por 16 años más. El territorio asignado desde 1894 fue todo el litoral del Pacífico mexicano, de frontera a frontera, incluyendo las Islas Marías, pero excluyendo los litorales orientales del Golfo de California, así como las pequeñas zonas concesionadas en las islas aledañas a la Bahía de La Paz. Éstas pertenecían a la Compañía Perlífera de San José ubicada en la isla del mismo nombre, dirigida por Manuel Romero Rubio, y a la sociedad de los hermanos González y Ruffo -islas Espíritu Santo y Cerralvo-. Ambas compañías locales obtuvieron su concesión desde 1884 y en ellas Gastón Vives desarrolló las actividades de la cCCP, que explicaremos en el siguiente apartado (Carińo y Monteforte 1999).

La política de concesiones territoriales para la extracción de nácar y perlas representa el clímax del extractivismo de las minas marinas del Golfo de California y del Pacífico mexicano. Generó grandes fortunas, la expatriación de los beneficios generados por la exportación de la riqueza perlera, y la exclusión de la población local del aprovechamiento de los recursos marinos. Esto último se exacerbó en las costas sudoccidentales del golfo, ya que ahí se concentraban los mejores placeres perleros, este recurso interesaba más a La Mangara y se le había otorgado legalmente de manera exclusiva. Por esa razón, La Mangara ejercía una estricta vigilancia de las embarcaciones que surcaban las aguas sudpeninsulares del golfo, impidiendo cualquier actividad de pesca. Salvo las armadas perleras de la CCCP, todas las demás pertenecían a La Mangara y cualquier actividad comercial de nácar y perlas (salvo las llevadas a cabo por la CCCP) era supervisada por sus representantes. De tal manera, todas las actividades pesqueras que no fueran realizadas desde la playa, eran consideradas sospechosas y quienes habían osado realizarlas eran perseguidos y encarcelados. Además el trabajo en las armadas perleras dependía solamente de dos empleadores: La Mangara y la CCCP. La primera fue triste- 
mente famosa por el trato cruel que infligía a sus trabajadores, así como por la dureza de sus castigos; especialmente sobre aquellos que eran acusados de haber pescado ilícitamente en el territorio de su concesión, aunque fuera sólo pesca de subsistencia (Cariño 1998).

Esta situación de injusticia alentó la formación de una importante resistencia en la población paceńa cuya alimentación dependía de la pesca y que tenía por principal fuente de empleo el trabajo en las armadas. Desde 1910, en La Paz buzos, pescadores y armadores contrarios a La Mangara, e incluso parte de sus empleados, se organizaron para solicitar a Porfirio Díaz que conminara a La Mangara a reducir sus maltratos y a flexibilizar su actitud. En respuesta, la compañía británica autorizó a particulares la pesca en los territorios de su concesión, pero los términos arbitrarios en los que podía desarrollarse esa actividad fueron considerados una burla por parte de los inconformes. ${ }^{1}$ La caída del porfiriato animó a los miembros del "Movimiento de la pesca libre" a radicalizar sus demandas, sólo tenían una solicitud: la rescisión de la concesión de La Mangara. Esta petición fue atendida por el gobierno del presidente Francisco I. Madero, quien el 28 de mayo de 1912 firmó el decreto que puso fin a los abusos de La Mangara y la pesca fue declarada por fin libre. Ya que la concesión era válida por veinte años más, el gobierno se comprometió a pagar una indemnización por $\$ 300,000$ pesos en tres años, lo que significó un alto costo para el joven gobierno revolucionario. ${ }^{2}$ El movimiento de la pesca libre también solicitó que la concesión de la СССР no fuera rescindida, pues, reconocían que sin su papel reproductor el recurso se agotaría y ya de nada serviría que ahora todos pudieran hacerse a la mar por el botín.

\section{Cultivo de ostras Perleras y PERlicultura \\ en el Golfo de California (I9O3-20 I 5)}

En la historia de las granjas perleras se reconoce el papel pionero de William Saville-Kent en Thursday Island, Australia. Este científico

\footnotetext{
${ }^{1}$ ANPlM, La Paz 1910, AjDbcs Procesos Penales, exp. 26/910.

${ }^{2}$ Ahplm, México, 1912, Fomento, vol. 569, exp. 147.
} 
británico desarrolló una pequeña instalación de cría rudimentaria para P. maxima, la gigante del género Pinctada. Aparte de comercializar concha y media-perla, se le atribuye la técnica de cirugía original para producir perla libre, idealmente esférica (George 2008). Sin embargo, la primera experiencia exitosa de cultivo de ostras perleras a escala industrial en el mundo se llevó a cabo en la Bahía de La Paz. El artífice de este importante logro científico, tecnológico y comercial fue el sudcaliforniano de origen francés Gastón J. Vives, quien fundó en 1903 la СCCP, asociándose con la familia Ruffo para aprovechar la concesión que ésta tenía de las islas Espíritu Santo y Cerralvo. En la última década del siglo xIx, Vives estudió bioquímica en París, donde advirtió la expectativa que se tenía en relación con el descubrimiento del cultivo de las ostras perleras. La sobreexplotación de este valioso recurso era una constante en todas las regiones perleras, y la escasez de perlas y nácar preocupaba a los poderosos empresarios que basaban sus fortunas en su explotación y comercio. También en Francia, Vives aprendió la técnica del cultivo de mejillón y ostión. Por otra parte, en La Paz gozaba de una posición privilegiada: fue presidente municipal (de 1890 a 1911), fungió como representante de la Compañía Perlífera del Golfo de Cortés por lo que entendía bien el trabajo de las armadas perleras y conocía profundamente el espacio marino y costero regional.

Aprovechando esta ventajosa coyuntura, a los pocos años de haber fundado la CCCP, Vives cumplió el pronóstico del naturalista Lyster Jameson, quien aseguraba que "quien resolviera el problema del cultivo de la madreperla, no sólo tendrá el privilegio de hacer progresar la ciencia y la industria, sino que su nombre merecerá el honor de ser comprendido entre los fundadores de imperios" (1914, 12). Este privilegio fue reconocido por la Académie National des Sciences en París, donde el nombre de Gaston Vives se encuentra grabado con letras doradas junto al de los principales científicos del mundo. En México somos pocos quienes hemos reseñado su gesta (Cariño y Monteforte 1999) y aprovechado sus conocimientos; ya que en buena medida el desarrollo de las tres etapas de cultivo extensivo de ostras perleras en las que se basó inspiraron el desarrollo moderno de la perlicultura en la región (Monteforte 2013). 
Estas etapas consistían en colecta de semilla, preengorda y cultivo tardío. Para su desarrollo, Vives innovó complejos y diversos artefactos, y construyó una impresionante infraestructura en la Estación de la CCCP que se encontraba en la bahía y estero San Gabriel, en la isla Espíritu Santo. Destacan la complejidad de la operación de colecta y la construcción de un dique marino de $500 \mathrm{~m}$ de longitud que permitía el funcionamiento de un sistema de 36 canales y esclusas, donde se desarrollaba la preengorda. Para operar tan vastos sistemas empleó 600 trabajadores $(10 \%$ de la población paceña), poseía una importante flota, e incluso aprovechaba la producción de sus ranchos agropecuarios para alimentar a sus empleados y a sus familias. En los once ańos de operación que duró la CCCP su crecimiento fue constante y rápido, logró cultivar diez millones de madreperlas y llegó a ser la principal fuente de empleo de La Paz. Miles de toneladas de concha con nácar de excelente calidad fueron exportadas a los mercados europeos y cientos de perlas extraordinarias continuaron alimentando las joyerías parisinas (Monteforte y Cariño 2012).

Es importante subrayar que Vives no realizó perlicultura comercial. Sin duda estaba al tanto de los trabajos de científicos europeos como Luis Boutan y Carl Linnaeus, así como de los experimentos de Saville-Kent. Pero en aquella época la venta de perlas cultivadas era impensable para un honrado empresario como Vives, ya que eran consideradas un fraude (Cariño 1996b). Además, era innecesaria ante la elevada incidencia de perlas naturales de excelente calidad en las ostras cultivadas por la СCCP que le permitía valiosísimas cosechas.

Pero el éxito conlleva celos y envidias, y el poder de Vives concluyó con el porfiriato, dejándole a merced de sus enemigos. Fue así como el 18 de julio de 1914, Miguel L. Cornejo en el revuelo imperante en la Revolución, abusó de su cargo como coronel del ejército constitucionalista para destruir la cCCP. Vives salvó la vida nadando hacia un buque estadounidense que se encontraba anclado en la Bahía de La Paz y huyó hacia la capital de la república donde solicitó en vano durante varios ańos la reparación de los dańos y apoyo para reanudar el cultivo. Las negociaciones nunca tuvieron éxito a pesar de que Vives propuso interesantes ideas como la creación de ejidos 
marinos para practicar la acuacultura. Mientras tanto, la riqueza perlera del Golfo de California menguaba rápidamente debido a la ausencia del papel reproductor de la СССР (Cariño 2000).

En 1939, las armadas encontraron en el fondo marino grandes cantidades de ostras perleras muertas. Se culpó a los japoneses de haber envenenado el mar para eliminar un competidor, pero la causa fue el efecto devastador que en las poblaciones sobreexplotadas de estos sensibles animales tuvo el aumento de salinidad del agua marina provocada por el embalsamiento del río Colorado. Vives murió ese mismo año, pobre y decepcionado. Presagiando la cercanía de su muerte, en 1935, redactó un interesante manuscrito en el que ofreció su legado de experiencia y, pese a todo, un soplo de esperanza y optimismo, al que tituló: El porvenir de la Baja California está en sus mares (Cariño 2000). En esta obra alienta el aprovechamiento de la riqueza marina de manera sustentable, mediante la acuacultura y no explotando un inagotable stock. Ahora se ha demostrado lo que hasta hace unas cuantas décadas pocos reconocían: los recursos marinos, si bien renovables hasta cierto punto, se agotan, e inclusive se extinguen al ser sobreexplotados. Vives fue uno de los pioneros en tener esa certeza, ya que las ostras perleras son uno de los primeros recursos marinos altamente valorados que se agotaron por extracción desmedida.

\section{Desarrollo de las granjas perleras y producción de perlas cultivadas}

$\mathrm{Al}$ margen de la controversia en considerar a Mikimoto o a SavilleKent como el inventor de las perlas cultivadas (George 2008), la factibilidad de su producción, aunada a la extinción comercial de las perlas naturales (debido al agotamiento de los placeres en todas las regiones del mundo), explica la apertura del estricto mercado de la joyería a las perlas cultivadas desde los años veinte (Cariño 1996b). Al término de la Primera Guerra Mundial, empezaron a circular abundantes perlas de excelente calidad, pero de dudosa uniformidad. Sólo mediante rayos $\mathrm{x}$ era posible distinguir las perlas cultivadas (portadoras de un núcleo esférico grande) de las naturales. Además, en los ańos veinte, el enriquecimiento de la clase media 
americana y la euforia del derroche, provocó un incremento inusitado en la demanda de perlas que sólo las cultivadas podía satisfacer.

Había iniciado la época de las perlas cultivadas, y así como a principios del siglo xx el cultivo de ostras perleras era el proceso crucial ansiado por el negocio perlero, a partir de la segunda posguerra lo fue la perlicultura. En 1949, los estadounidenses ordenaron la publicación de un documento que describe la tecnología de cultivo y perlicultura en la especie japonesa Pinctada martensii (especies chica), llamada comercialmente Akoya (Cahn 1949). Este documento develó las bases del conocimiento de la perlicultura y fomentó la investigación en la Akoya liderada por los científicos japoneses de la postguerra, quienes se convirtieron en los expertos mundiales de la materia.

Con base en este conocimiento, desde mediados de la década de 1960, surgieron granjas perleras en el Indo-Pacífico. Primero en la Polinesia Francesa y en el norte de Australia, luego en India, Islas Marshall, Myanmar, Filipinas, Indonesia, Tailandia, Melanesia, Kiribati y otras. Pero Japón continúa siendo el principal productor en $P$. martensii y posee fuertes inversiones en las más importantes granjas del mundo que cultivan en las especies de mayor tamaño ( $P$. maxima y $P$. margaritifera), las perlas de mejor calidad y precios exorbitantes. En el siglo Xxi han surgido granjas de ostras perleras de talla grande ( $P$. m. erythensis) en Egipto, Etiopía, y ( $P$. m. persica) en Irán, de talla mediana en el Golfo de California (P. mazatlanica y Pt. sterna) y de talla pequeña en el Caribe y Venezuela (Pt. colymbus y $P$. imbricata). Además, avances en la investigación han permitido la incorporación de varios moluscos en la producción de perlas, como abulón y caracol reina. Las perlas ya no son raras gemas, sino joyas valiosas, pero accesibles a una clientela mundial de clase media relativamente pudiente.

En los últimos ańos, la oferta ha crecido a la par de las granjas perleras que se han establecido gracias a la socialización del conocimiento científico-tecnológico de la perlicultura, que provoca bajos precios y menor calidad. Consecuentemente, el cultivo de nácar y perlas está hoy lejos de ser el enorme negocio que fue entre 1970 y 1990. No obstante, el derrumbe del mercado de perlas cultivadas 
no se debió al incremento de la producción en los países mencionados, éste sucedió cuando China inundó el mercado mundial de perlas medianas a pequeñas, de agua dulce y marinas. Hacia 2005, los chinos empezaron a incursionar con perlas marinas cultivadas en la madreperla $P$. chemnitzi (especie chica) y poco tardaron en producir masivamente semilla en laboratorio e instalar granjas perleras en cuanto sitio propicio hubiere en su extensa costa. Para desgracia de los cultivadores de ostras perleras chicas, las perlas libres de granja china inundaron el mercado de clase media con sus bajos precios y amplia distribución.

Los mercados de perlas en las grandes ciudades orientales evidencian que aventurarse a invertir en una granja perlera es incierto. Hay costales rebosantes de bonitas perlas Mabé, esféricas y subesféricas, de todos tamaños y colores, y de perlas de río. El ojo experto puede distinguir una Golden Pearl filipina o una Black Pearl polinesia, que vale miles de dólares la pieza, de una perla semejante china que se vende a menos de 50 USD en cualquier puesto callejero. No obstante, atractivas piezas de joyería con estas perlas son cada vez más frecuentes en los mercados populares europeos y americanos, donde gozan de amplia aceptación por la clientela.

Aunque los joyeros de renombre vean con cierto desprecio lo que consideran bisutería, las perlas chinas han provocado cambios importantes en la perlicultura. Por ejemplo, los productores no chinos buscan estrategias para certificaciones de origen mediante uso de rayos x y luz infrarroja (Kiefert et al., 2004), y se está estudiando la inserción de chips electrónicos en el núcleo. Aun así, el mercado suntuario, en general, sufre vaivenes y el precio global de las perlas ha bajado considerablemente, lo que impacta negativamente las otrora millonarias ganancias de las granjas perleras.

Sin duda, estos bellos objetos marinos no dejarán de tener el ancestral atractivo que ha hechizado a todo tipo de clientela durante siglos, por lo que es pertinente suponer que el éxito de una granja perlera depende hoy más de aspectos de mercadotecnia que de limitaciones tecnológicas (Monteforte y Cariño 2013). Sin embargo, el esfuerzo de los granjeros pequeńos y medianos por mantenerse en el mercado, así como aquellos que deseen iniciar la producción, se 
enfrentan a una despiadada competencia en mercados saturados con perlas al mayoreo.

Ante esta situación, ya no es sensato plantear modelos perleros rústicos, artesanales o comunitarios, de pequeña escala y reducido volumen de producción. Es mejor aprovechar los avances en ciencia y tecnología que incluyen la cría simultánea de ostras perleras y de otras especies marinas. Algunas modalidades (aquaponia y cultivo multitrófico, integrado o policultivo) a menudo se asocian con ingeniería acuícola y biotecnologías (nutrición y genética). Los moluscos bivalvos (comestibles y ostras perleras) y algunas pequeñas especies de peces e invertebrados con potencial en el mercado de acuarios marinos, se prestan bien a la cría en modalidad de policultivo en escenarios que aun a pequeña escala pueden ser rentables. Es en este punto donde destacan las características zoogeográficas de una región en particular, dado que el conjunto de las especies comerciales puede ser diferente en cuanto al número y valor. El Golfo de California tiene excelente potencial por la presencia de dos especies de ostras perleras valiosas y una docena de bivalvos gourmet (mano de león, hacha, pata de mula, voladora, catarina, blanca, indio, burra y ostión nativo). También es importante considerar las especies ornamentales, cuyo potencial hasta la fecha es aún inexplorado. En la siguiente sección examinaremos algunas experiencias que se han llevado a cabo en la región de estudio.

\section{Tránsito a la maricultura moderna: una posibilidad para la construcción de la sustentabilidad regional (1940-2015)}

En 1940, cuando la pesca de nácar y perlas en el Golfo de California había caído en desgracia, llegó a La Paz un japonés llamado Matsuii Yamamoto quien obtuvo permisos para captura-encierro de adultos de P. mazatlanica con el fin de realizar cirugía de perla libre. Ésta es la modalidad que había innovado Saville-Kent y que se practica actualmente en el norte de Australia con P. maxima bajo reglas draconianas (por ejemplo, restricción de áreas y temporadas de pesca, de talla mínima, de profundidad, de tipo de equipo, de cuotas de captura y tamaño de la flota, y obligación de proveer reportes, so pena de 
cuantiosas multas, decomisos y prisión, y prohibición permanente de seguir pescando). Los resultados fueron desastrosos, con altísima mortalidad postcirugía y expulsión de núcleos en los pocos animales que encontraron. De nuestro conocimiento, el Sr. Yamamoto regresó a su país y no se volvió a saber más de él ni de sus socios.

Entre 1970 y 1985, hubo una docena de proyectos que intentaron recuperar la productividad perlera en el Golfo de California, prácticamente, todos en la Bahía de La Paz; unos cuantos incidieron en la ciencia y la tecnología del cultivo, pero la mayoría se enfocaron sólo en producir perlas. Entre éstos destaca la presencia del experto griego-australiano Denis George quien entre 1970 y 1972 ayudó a un grupo de empresarios mexicanos para establecer una granja en la Bahía de La Paz, que fue "decomisada" durante la presidencia de Luis Echeverría justo antes de la primera cosecha de Mabe. Destaca también la visita a La Paz en 1979 de Shoei Shirai y Yoshiyasu Sano, dos expertos japoneses famosos en la época, el resultado fue el mismo de 1940, otro gran fiasco al realizar perlicultura en las escasas madreperlas silvestres.

La acumulación de fracasos fue creando escepticismo y falta de interés en instancias académicas y gubernamentales hacia toda nueva iniciativa en torno a granjas perleras y perlas. No obstante, en 1987, logramos colectar en un pequeño sistema experimental un puñado de semillas de madreperla, lo que representó el aval para arrancar la investigación sistemática a través de un austero proyecto Conacyt. $^{3}$

El congreso internacional Pearls'94 realizado en Honolulu, Hawai, es considerado por muchos en el gremio perlero como un hito en la perlicultura moderna. En ese evento, presentamos once trabajos del Grupo Ostras Perleras del CIBNOR cuyo contenido representaba ya un paquete tecnológico consolidado. Colegas del ITESM campus Guaymas y la UABCS en La Paz, que asistieron al con-

${ }^{3}$ Desde entonces y hasta 2001, el coautor de este artículo, ha logrado obtener y finalizar exitosamente 16 proyectos nacionales e internacionales, incluyendo tres más de Conacyt y otros de los fondos siguientes: sIMAC, Fondo Mexicano para la Conservación de la Naturaleza, conABio, International Foundation for Science, ECOs-ANUIEs (con Francia) y la Fundación McBean-Island Pearls. 
greso aprovecharon el cúmulo de información para iniciar sus propios proyectos y empresas. Actualmente se conocen tres granjas activas en México en Guaymas, La Paz y Cozumel. Las dos primeras trabajan principalmente concha nácar (Pt. sterna); la de Cozumel con las dos especies caribeñas chicas, P. imbricata y Pt. colymbus. También se están haciendo algunos estudios de cultivo extensivo experimental en Acapulco y Puerto Escondido, Oaxaca.

Entre 1994 y 2001, gracias a los proyectos aprobados, el Grupo Ostras Perleras realizó investigaciones tanto para terminar de conocer la respuesta de las especies ante los sistemas de cría y las rutinas de manejo, como estudios relacionados con la perlicultura. $\mathrm{Al}$ mismo tiempo, se empezó a buscar vinculación con grupos de pescadores ribereños con el fin de socializar el conocimiento. Por desgracia, ninguna de estas iniciativas pudo concretarse debido principalmente a que el sistema oficial de ciencia y tecnología ofrecía (y ofrece) pocas alternativas para apoyar a comunidades pobres (López-Zárate 2008). En las instituciones mexicanas se crearon instancias administrativas encargadas de privatizar las innovaciones de sus investigadores; por ejemplo, a través de patentes y registros de propiedad, privilegiando acuerdos con empresarios mexicanos y extranjeros. El CIBNOR no fue una excepción. Sin embargo, en todo momento nos opusimos a ceder al mejor postor lo que considerábamos patrimonio colectivo de la comunidad, para lo cual decidimos fundar una entidad independiente denominada PERLAMAR S. de R.L. cuya misión fue abrir una granja perlera para entrenar pescadores ribereños en la tecnología de cultivo y perlicultura, y apoyarles para formar una granja comunitaria. Evidentemente, esto no gustó a las autoridades institucionales quienes obligaron el cierre de PERLAMAR sin que ésta realmente hubiera funcionado como se pretendía. Poco tiempo después el Grupo se desmembró.

Después del 2001, prácticamente, se dejó de hacer investigación en torno a las ostras perleras, salvo experimentos de corta duración en laboratorio encaminados más a publicar y graduar alumnos en corto tiempo, que a buscar la optimización del cultivo en campo con miras a consolidar una granja perlera. Pero la idea inicial, de hacer de la perlicultura una alternativa productiva para el sector so- 
cial regional prevaleció y, desde 2002, el trabajo en ese sentido ha continuado de forma individual. Mientras tanto, el mundo perlero cambió como señalamos antes, por lo cual tuvimos que adaptar los proyectos tanto a esa realidad de mercado como a los avances científicos y técnicos modernos. Así, proseguimos con dos estrategias que giran en torno a la perlicultura.

En la primera se logró validar técnicas de perlicultura en abulón con proyectos piloto en Ensenada ${ }^{4}$ y en Isla Natividad. ${ }^{5}$ Las cooperativas de "la Pacífico Norte" (FEDECOOP) han mostrado poco interés en producir perla de abulón, tal vez porque la región tiene poca capacidad instalada para cultivar abulones durante 6 años. No obstante, en Isla Natividad, con apoyos gubernamentales se logró construir y equipar un espacio para cultivar miles de abulones durante los casi 6 años que se requieren para cosechar perlas de excelente calidad; su continuidad permitirá escalar la producción anualmente.

La segunda estrategia consistió en explorar el policultivo de moluscos y especies ornamentales en la Bahía de La Paz. Este proyecto inició con un muy precario capital semilla en beneficio de una cooperativa pesquera, obtenido a través de CONAPESCA en 2009. Fue posible instalar en el mar una parte de los sistemas e involucrar en el trabajo a los miembros de la cooperativa. Los resultados confirmaron el potencial de esta modalidad y la validez de las proyecciones bioeconómicas, que podrían superar toda expectativa. Una serie de problemas provocaron la suspensión de los trabajos, pero de los 70 mil animales que tenía el sistema antes de que se abandonara por falta de fondos y vandalismo, se recuperaron 20 mil individuos de 6 meses de edad que fueron sembrados para repoblamiento.

\section{Conclusión}

La primera impresión tras la narrativa de la historia de las perlas y el nácar en el Golfo de California sería una suerte de fatalismo, podría llegarse a creer que tan bellas y codiciadas gemas encierran en su

${ }^{4}$ Fondos Mixtos CONACYT-BC 2004-2006.

${ }^{5}$ Walton Family Foundation-COBI A.C. 2011-2015. 
búsqueda una maldición. En cierta forma es cierto si consideramos la codicia y la ambición que avivan. Sin embargo, esto es sólo una parte de la historia, aquella que no toma en cuenta los efectos detonantes que la pesca, el cultivo y el comercio de nácar y perlas tuvieron en la estructura económica regional. Especialmente benéficas han sido las consecuencias de las diferentes experiencias de cultivo, ya que además de generar empleos directos y actividades productivas indirectas (desde la agricultura hasta la joyería) han tenido un impacto positivo en el ambiente marino.

Por lo tanto, la historia ambiental de las actividades perleras en el Golfo de California nos permite sacar conclusiones importantes, si se piensa en un futuro esperanzador por el hecho de tener la capacidad de aprender de los desaciertos y la capacidad de luchar por construir la sustentabilidad necesaria para permanecer habitando la Tierra.

En este sentido hay que enfatizar en lo posible y lo conveniente. Tanto histórica como actualmente se ha demostrado que las ostras perleras son un recurso económico de gran valor que puede ser aprovechado de manera sustentable mediante el cultivo, es decir, que se trata de un recurso renovable y manejable. Además de beneficiar a los productores permite el repoblamiento silvestre de las especies que se cultivan. También hay que considerar que la tecnología es nacional, se encuentra disponible de manera pública (ya que nunca se aceptó patentar) y fue diseñada para que fuera económica y de manejo sencillo, accesible mediante la capacitación y en condiciones precarias en campo. Ha sido demostrado que el cultivo de ostras perleras en condiciones de policultivo es una alternativa productiva viable para las comunidades de pescadores ribereños, por lo que uno de sus efectos colaterales podría ser reducir el esfuerzo de pesca y su presión sobre el ambiente marino.

La historia que hemos analizado también muestra que el extractivismo sólo ha tenido consecuencias nefastas, tanto en el pasado como en el presente. En este caso, consideramos que la aplicación de la ciencia producida en instituciones de investigación científica públicas, que es ofrecida al capital y negada a la sociedad, es una forma más de extractivismo. Esto es así porque acentúa la asimetría en el 
ejercicio del poder e incrementa la desigualdad social. Pero también sus consecuencias en el medio marino son negativas ya que la codicia inherente a esa ideología y práctica social provoca ceguera ante los riesgos y daños ambientales, siempre y cuando éstos no afecten la productividad de la empresa. Finalmente, en el extractivismo prevalece el pensamiento colonial, en el que sólo importa la ganancia de corto plazo y las sociedades y territorios locales son prescindibles por ser sustituibles.

Por lo tanto, una de las estrategias, que se debería considerar en la construcción de la sustentabilidad regional, consiste en revalorar el legado de Vives: El futuro de la Baja California está en sus mares; siempre y cuando éstos sean aprovechados en beneficio de la sociedad regional con base en actividades que beneficien el medio marino. Las ostras perleras han sido actores importantes en la historia colonial y poscolonial del extractivismo en el Golfo de California, pueden tener un papel igualmente importante en la construcción de la sustentabilidad regional.

\section{BiBLIOGRAFÍA}

Brusca, Richard C. y H.R. WAllernsteIn. 1979. "Zoogeographic Patterns of Idoteid Isopods in the Norheast Pacific, With a Review of Shallow Water Zoogeography of the Area". Bulletin of the Biology Society (3): 67-105.

CaHn, A. R. 1949. "Pearl Culture in Japan". Fish. Leafl., US Fish Wildl. Serv. (357): 1-91.

CARIÑo, Micheline y Aurora BRECEDA. 1995. Ecohistoria de los californios. La Paz: UABCS.

CARIÑo, Micheline. 1996. Historia de las relaciones hombre naturaleza en Baja California Sur, 1500-1940. La Paz: Eds. Universidad Autónoma de Baja California Sur.

CARIÑo, Micheline. 1996a. "Concesiones territoriales para la inversión extranjera en Sudcalifornia durante el siglo xIX". En Inversiones y empresarios extranjeros en el noroccidente de México, siglo $X I X$, ed. Jaime Olveda, 29-49. México: El Colegio de Jalisco.

Cariño, Micheline. 1996b. "The Cultured Pearl Polemic. Science 
and Business went Face to Face when Cultured Pearls First Entered the International Market”. World Aquaculture 27(1): 42-44. Cariño Olvera, Martha Micheline. 1998. "Les mines marines du golfe de Californie: Histoire de La Paz à la lumière de ses perles, 1500-1940”. Tesis de Doctorado, École des Hautes Etudes en Sciences Sociales de París.

Cariño, Micheline y Mario Monteforte. 1999. El primer emporio perlero sustentable del mundo: la Compañia Criadora de Concha y Perla de la Baja California S.A., y sus perspectivas para Baja California Sur. México: UABCS, SEP, FONCA-CONACULTA.

CAriño, Micheline y Mario Monteforte. 2006. Une historie mondiale des perles et des nacres : pêche, culture et commerce. París: Col. Maritimes, Ed. L'Harmattan.

Cariño Olvera, Micheline. 2000. El porvenir de la Baja California está en sus mares. Vida y legado del primer maricultor de América: Don Gastón J. Vives. México: UABCS-SEP.

Coronado, Moisés. Paleografía y notas. 1982. Auto de posesión del Puerto y Bahia de la Santa Cruz, 3 de mayo de 1535. La Paz: Fonapaz.

Del Río, Ignacio. 1985. A la diestra mano de las Indias. La Paz: Gob. del Estado.

Diguet, Léon. 1895. "Pêche de l'huitre perlière dans le Golfe de Californie”. Bulletin de la Société Centrale d'Aquaculture de France. Tome vir (2eme serie) (1-2) (enero-febrero): 4-17.

Esteva, José María. 1977. "Memoria sobre la pesca de la perla en la Baja California (1857)”. En Las perlas de Baja California, 30-45. México: Departamento de Pesca.

Galstoff, Paul. 1950. The Pearl Fishery of Venezuela. Washington: Special Scientific Report-Fisheries. N. 26, US Department of the Interior.

George, Denis. 2008. "Debunking a Widely Held Japanese Myth: Historical Aspects on the Early Discovery of the Pearl Cultivating Technique". Pearl World (10): 1-7.

Jameson, Lyster. 1914. “The Pearling Industry”. Scientific American Supplement LXXVII(1983) (enero 1914): 12-16.

Kiefert, L., D. M. Moreno, E. Arizmendi, H. A. Hanni y S. 
ELEN. 2004. "Cultured Pearls from the Gulf of California, Mexico". Gems \& Gemology, 40(1): 26-38.

Kristin, Joyce y Addison Shellei. 1992. Pearls, Ornament and Obsession. Londres y Nueva York: Thames and Hudson, Simon \& Schuster.

López-ZÁrate, R. 2008. "Los valores de la ciencia en el subsistema de educación superior”. En Cultura mexicana: revisión y prospectiva, ed. F. Toledo, E. Florescano y J. Woldenberg, 31-60. México: Taurus Santillana Ediciones Generales.

Mathes, Miguel. 1973. Sebastián Vizcaino y la expansión española en el océano Pacifico (1580-1630). México: IIH-UNAM.

Monteforte, Mario. 2005. "Biología, ecología y cultivo de la madreperla Calafia, Pinctada mazatlanica (Hanley 1856), y la concha nácar arcoiris, Pteria sterna (Gould 1852) en Bahía de La Paz, Baja California Sur, México”. Tesis PhD en Ciencias Biológicas, Universidad de La Habana, Cuba.

. 2013. Instalación y operación de granjas perleras: un manual para Pinctada mazatlanica y Pteria sterna. Saarbrücken: Editorial Académica Española.

Monteforte, Mario y Micheline Cariño. 2012. "Episodes of Environmental History in the Gulf of California: Fisheries, Commerce and Aquaculture of Nacre and Pearls." En A land Between Waters. Environmental Histories of Modern Mexico, ed. Christopher R. Boyer, 245-276. Tucson: The University of Arizona Press.

Monteforte, Mario y Micheline Cariño. 2013. "Condiciones para el desarrollo de granjas perleras y producción de perlas: estado del arte, potencial y perspectivas". Rev Biol Mar Oceanog 48(1): 1-16.

Narchi, N. E., S. Cornier, D. M. Canu, L. E. Aguilar-Rosas, M. G. Bender, C. Jacquelin, R. De Wit. 2014. "Marine Ethnobiology a Rather Neglected Area, which Can provide an Important Contribution to Ocean and Coastal Management". Ocean \& Coastal Management (89): 117-126.

Reygadas, Fermín y Guillermo VelázQuez. 1983. El grupo Pericú de la Baja California. La Paz: Fonapaz.

Saslis-Lagoudakis, C. H. y A. C. Clarke. 2013. "Ethnobiology: 
the Missing Link in Ecology and Evolution”. Trends in Ecology \& Evolution 28(2): 67-68.

WADA, K. 1961. "Crystal Growth of Molluscan Shells”. Bull Natural Pearl Res Lab (7): 703-828. 